\title{
Electronic cigarette use as an aid to quit smoking in the representative Italian population PASSI survey
}

\author{
Giuseppe Gorini ${ }^{\mathrm{a}}$, Gianluigi Ferrante ${ }^{\mathrm{b}, *}$, Elisa Quarchioni ${ }^{\mathrm{b}}$, Valentina Minardi ${ }^{\mathrm{b}}$, Maria Masocco ${ }^{\mathrm{b}}$, \\ Pirous Fateh-Moghadam ${ }^{\mathrm{c}}$, Stefano Campostrini ${ }^{\mathrm{d}}$, Paolo D'Argenio ${ }^{\mathrm{e}}$, Daniela Galeone ${ }^{\mathrm{f}}$, on behalf of the \\ PASSI coordinating group ${ }^{1}$
}

\footnotetext{
a Occupational \& Environmental Epidemiology Section, Cancer Research \& Prevention Institute (ISPO), Florence, Italy

${ }^{\mathrm{b}}$ National Institute of Health (ISS), Rome, Italy

c Health Education Service, Provincial Agency for Health Services, Trento, Italy

d Department of Statistics, Ca' Foscari University, Venice, Italy

e PASSI coordinating group, Italy

${ }^{\mathrm{f}}$ Italian Ministry of Health, Center for Disease Prevention and Control, Rome, Italy
}

\section{A R T I C L E I N F O}

\section{Article history:}

Received 21 February 2017

Received in revised form 20 June 2017

Accepted 22 June 2017

Available online 23 June 2017

\section{Keywords:}

E-cigarettes

Smoking cessation method

Cross-sectional survey

Italy

\begin{abstract}
A B S T R A C T
This study explored electronic cigarette (e-cigarette) use as an aid to quit smoking and compared abstinence rates for different quitting methods in a representative sample of the Italian population.

In the 2014-2015 PASSI survey, the ongoing Italian behavioural risk factor surveillance system, 6112 adults who smoked and made at least one quit attempt in the previous 12 months, were categorized into three groups according to the method used in their most recent quit attempt: e-cigarette only, no aid, other quitting methods (medications; programmes delivered in smoking cessation services; other unspecified methods). The primary outcome was self-reported abstinence for a period $\geq 6$ months, adjusted for potential confounders.

Eleven percent used e-cigarettes only, $86 \%$ no aid, $3 \%$ other quitting methods. Smoking abstinence was reported among $9 \%$ of those using no aid; $8 \%$ of e-cigarette users; $15 \%$ of those using other methods. No significant differences in abstinence were observed for e-cigarette users compared with those reporting no aid (adjusted Prevalence Ratio $[\mathrm{aPR}]=0.81 ; 95 \%$ Confidence Interval $(\mathrm{CI})=0.58-1.14)$. Changing the reference group to e-cigarette users, those using other quitting methods were significantly more likely to report abstinence than e-cigarette users (aPR $=1.76 ; 95 \% \mathrm{CI}=1.07-2.88)$.

One out of ten smokers who attempted to quit in 2014-2015 in Italy used e-cigarettes. E-cigarettes users were as likely to report abstinence as those using no aid, but were less likely to report abstinence than users of established quitting methods. Further studies are needed to understand the relationship between e-cigarette types used to quit and abstinence rates.
\end{abstract}

(c) 2016 Elsevier Inc. All rights reserved.

\section{Introduction}

Smoking is estimated to kill each year 5.8 million people world-wide (GBD 2013 Risk Factors Collaborators et al., 2015), and about 71,000

\footnotetext{
* Corresponding author at: National Institute of Health, National Center for Drug Research and Evaluation, Viale Regina Elena, 299, 00161 Rome, Italy.

E-mail address: gianluigi.ferrante@iss.it (G. Ferrante).

${ }^{1}$ Members of the PASSI coordinating group: Valentina Possenti, Benedetta Contoli, Alberto Perra, Stefania Salmaso, National Institute of Public Health, Rome, Italy; Mauro Ramigni, Department of prevention Ulss 9, Treviso, Italy; Nicoletta Bertozzi, Regional Social Health Agency Emilia-Romagna Region, Bologna, Italy; Giuliano Carrozzi, Department of Public Health, Ausl Modena, Modena Italy; Angelo D'Argenzio, Department of Prevention, Ausl Caserta 2, Caserta, Italy; Massimo Oddone Trinito, Department of Prevention, Ausl Roma C, Rome, Italy; Marco Cristofori, USL Umbria 2, Terni, Italy; Amalia De Luca, Asp Cosenza, Cosenza, Italy; Stefania Vasselli, Ministry of Health, Rome, Italy.
}

people in Italy (Gallus et al., 2011). E-cigarettes are devices that vaporise a chemical liquid mixture, in most cases including nicotine, which is inhaled by users. A few years after e-cigarette entrance in the market, its popularity and use substantially grew worldwide (Green et al., 2016). In 2014 prevalence of ever and current e-cigarette users was among US adults $12.6 \%$ and 3.7\%, respectively (Schoenborn and Gindi, 2015). Among Europeans prevalence of ever users was $7.2 \%$ in 2012 and $11.6 \%$ in 2014 , whereas prevalence of current users was $1.8 \%$ in 2014 (Filippidis et al., 2017). In Italy in 2013 ever e-cigarettes use was 6.8\% (about 3.5 million Italians aged $\geq 15$ years), and current e-cigarette use was 1.2\% (about 600,000 Italians) (Gallus et al., 2014).

The scientific community has sparked a huge debate to understand whether e-cigarettes should be considered a disruptive technology that increase quitting smoking and provide a safe alternative to cigarettes, or a threat to tobacco control that will allow the tobacco industry 
to subvert policies, renormalize smoking, recruit new smokers, and promote smoking in young people (Green et al., 2016; Yeh et al., 2016). One Cochrane review suggested that there is evidence from two randomized controlled trials (RCTs), that e-cigarettes may help smokers to quit in the long term compared with placebo e-cigarettes, even though under the GRADE system the overall quality of the evidence was judged as 'low' or 'very low', because of imprecision due to the small number of trials (Hartmann-Boyce et al., 2016). Two recent reviews that included not only RCTs but also cross-sectional and cohort studies, concluded that the evidence in support of e-cigarettes' effectiveness in helping smokers quit is inconclusive or even negative (Kalkhoran and Glantz, 2016; Malas et al., 2016). Importantly, the quality of the evidence in support of e-cigarettes' effectiveness in helping smokers quit, according to the GRADE system, was again assessed as very low to low (Malas et al., 2016). Considering only studies with a moderate or strong quality score (Malas et al., 2016), 10 studies other than RCTs examined the relationship between e-cigarette use and smoking status in the real world by surveying regular e-cigarette users (Tackett et al., 2015; Lechner et al., 2015; Goniewicz et al., 2013; Dawkins et al., 2013; Polosa et al., 2014; Adriaens et al., 2014; Adkison et al., 2013; Christensen et al., 2014; Brown et al., 2014; Biener and Hargraves, 2015). Samples in 5 studies were not representative, and results have to be interpreted with caution (Tackett et al., 2015; Lechner et al., 2015; Goniewicz et al., 2013; Dawkins et al., 2013; Polosa et al., 2014). In studies with representative samples, evidence was mixed. In a longitudinal study, e-cigarette users at baseline were no more likely to report abstinence, even though they reduced their cigarette consumption (Adkison et al., 2013). One cross-sectional study on a representative sample of Kansas adults found that use of e-cigarettes was negatively associated with quitting after adjusting for socio-demographic and smoking characteristics (Christensen et al., 2014). This study, however, evaluated the association between quitting and the use of e-cigarettes for any purpose, not as an aid to quit. Another study assessed the effectiveness of e-cigarettes to quit in a representative sample of the English population, and found that e-cigarette users were $60 \%$ more likely to report abstinence in comparison to those using no aid or nicotine products over the counter (Brown et al., 2014). The most recent study, a cohort study on a representative sample of adults in 2 US metropolitan areas, found that daily e-cigarette users were 6 times more likely than non-users or triers to report abstinence, whereas non-daily users were 70\% less likely to quit compared to non users or triers (Biener and Hargraves, 2015). It is important to highlight that in the sensitivity analysis conducted in one of the two reviews on e-cigarettes' effectiveness, none of differences in study design (longitudinal, cross-sectional) were associated with significantly different results (Kalkhoran and Glantz, 2016).

The ongoing behavioural risk factor surveillance system PASSI (Progressi delle Aziende Sanitarie per la Salute in Italia) is a cross-sectional survey conducted each year since 2008 on representative samples of the Italian population aged 18-69 years. The PASSI survey has been tracking smoking cessation methods used in the most recent quit attempt made within 12 months before the interview (Baldissera et al., 2011; The Italian behavioral risk factor surveillance system, n.d.; Baldissera et al., 2014; D'Argenzio et al., 2011). Main objectives of the current study were: a) to explore the use of electronic cigarette (e-cigarette) as an aid to quit smoking in 2014-2015; b) to estimate the abstinence rate among those who used e-cigarettes to quit; $c$ ) to compare abstinence rates for different smoking cessation methods (e-cigarette, other quitting methods, no aid).

\section{Methods}

\subsection{Population data source}

The protocol of the annual PASSI survey was approved in 2007 by the Ethics Committee of the Italian National Institute of Public Health (Baldissera et al., 2011). The sample for the annual PASSI survey is extracted from the Italian adult population aged 18-69 years ( $>41$ million at the beginning of 2015). Each of the 20 Italian regions comprises 1 to 22 Local Health Units (LHUs), which provide preventive and curative services for populations ranging from 40,000 to over 1 million people; LHUs are the data collection units for the PASSI survey. The target population includes all people aged 18-69 years residing in the LHU area. Eligible subjects are residents with an available telephone number and capable of being interviewed. In each LHU, a random sample is drawn monthly from the enrolment list of residents, stratified by sex and age (18-34, 35-49, and 50-69 years) proportionally to the size of the respective stratum in the general population. Both landline and cellular telephones are used for the interviews (Baldissera et al., 2011; The Italian behavioral risk factor surveillance system, n.d.; Baldissera et al., 2014; D'Argenzio et al., 2011).

\subsection{Data collection}

Specially trained personnel from the public health departments of each LHU administered telephone interviews through a standardized questionnaire, gathering information on a wide variety of health-related behavioural and preventive topics along with socio-demographic data. Informed consent was obtained from all participants. The data were anonymized and electronically recorded in a national database. Interviews collected during a calendar year were aggregated in an annual dataset. The LHU data are merged and analysed to obtain regional and national estimates. More details on methodological issues related to PASSI data collection have been described elsewhere (Baldissera et al., 2011; The Italian behavioral risk factor surveillance system, n.d.; Baldissera et al., 2014; D'Argenzio et al., 2011). In 2014-2015, 131 out of 139 (94\%) Italian LHUs participated in the PASSI survey. The population aged 18-69 years resident in the participating LHUs corresponded to $90 \%$ of the Italian population of the same age. The total number of interviews collected was 71,608 in 2014-2015. Response rate, calculated according to the American Association for Public Opinion Research RR4 standard (American Association for Public Opinion Research, 2008), was $83 \%$ in 2014 and $82 \%$ in 2015.

For the current study, we used aggregated data from 6847 respondents in 2014-2015, who smoked cigarettes (including hand-rolled) daily or occasionally at the time of the survey or during the preceding 12 months, and had made at least one quit attempt in the preceding 12 months. Interviewers asked to them which method they used to quit in their last quit attempt. Possible answers were: (a) no aid; (b) e-cigarettes (collected since 2014 onwards); (c) medications (prescription drugs or Nicotine Replacement Therapy (NRT) over the counter); (d) smoking cessation programmes delivered in National Health System [NHS] Smoking Cessation Services (SSSs) that usually combine pharmacotherapy with behavioural support; (e) smoking cessation programmes not delivered in NHS-SSSs; (f) other unspecified methods, ( $g$ ) does not remember. Response options were mutually exclusive. Seventy-one respondents were excluded: 36 respondents did not answer to the question on quitting methods and 35 respondents answered they did not remember the quitting method used in the last attempt. We merged the answers on methods used to quit into three groups: those who used no aid; those who used e-cigarettes, and those who used "other methods", i.e., items (c), (d), (e), and (f).

The primary outcome was self-reported abstinence for a period greater than or equal to six months at the time of the interview. All the people reporting an attempt to quit smoking in the 12 months preceding the interview were asked "When did you stop smoking?", those who answered "six months or more" at the time of the interview were classified in the group "successful attempt" $(\mathrm{N}=583)$; those reporting being current smokers were classified in the group "failed attempt" ( $\mathrm{N}$ $=5529$ ); those responding "less than six months" were excluded from the analysis $(\mathrm{N}=664)$. Thus, the overall population under study is represented by 6112 individuals. 
In the statistical analysis we considered abstinent only those whose attempts were successful (more or equal to six months). In order to take into account nicotine dependence, we used as a proxy the average number of cigarettes smoked per day: less than one (occasional smokers), between one and 19 cigarettes (light smokers) and 20 or more (heavy smokers).

The PASSI survey also collected information on socio-demographic characteristics. Those included in this analysis were sex, age (18-34, $35-49$, or $50-69$ years), education level: low (none or elementary school, or junior high school) and high (high school, or university); geographic area of residence (Northern, Central Italy, or Southern Italy and major islands, according to the criteria of the Italian National Institute of Statistics). Economic status was assessed by asking: "With your monthly household income, how do you manage until the end of the month?" Answers were categorized into three groups: "very easily or easily" = None economic difficulties; "with some difficulties" = Some economic difficulties; "with many difficulties" = Many economic difficulties.

\subsection{Statistical analysis}

Complex survey design analyses using the Taylor series method for variance estimation were conducted in Stata 13 software (Stata Corporation, 2013). Percentage estimates were weighted, assigning each record a probability weight equal to the inverse of the sampling fraction in each LHU stratum (Baldissera et al., 2011; The Italian behavioral risk factor surveillance system, n.d.; Baldissera et al., 2014).

Bivariate associations between the use of different quitting methods and potentially confounding socio-demographic and smoking variables were assessed using the Chi-squared tests. Percentage estimates of successful quit attempts were calculated overall, by socio-demographic characteristics, by type of smokers, and by methods used to stop smoking. In order to study the association between quitting methods and smoking abstinence, a Poisson regression model with robust variance and hypothesis testing was used for estimating prevalence ratios adjusted for gender, age, education level, economic status, geographic area, and average number of cigarettes smoked per day (Petersen and Deddens, 2008; Zou, 2004).

\section{Results}

Eighty-six percent of the 6112 respondents included in this study, reported a most recent quit attempt in the last 12 months that was unaided, or supported by e-cigarettes (10.7\%), or by other smoking cessation methods (2.9\%) (Table 1). Thirty-four percent of those using other cessation methods, attempted to quit using medications; $33 \%$ using smoking cessation programmes delivered in NHS-SSSs; 9\% smoking cessation programmes not delivered in NHS-SSSs; $23 \%$ reported to have attempted with unspecified methods. The three main groups of quitting methods (unaided, with e-cigarettes; with other more official methods) did not differ by level of education and geographic area, but were associated with gender, age, economic status, and number of cigarettes smoked per day (Table 1$)$. In fact, men (11.7\%), respondents aged $35-$ 49 years (14.1\%), respondents with many economic difficulties (14.0\%), and heavy smokers (18.8\%) were significantly more likely to use e-cigarettes to stop smoking (Table 1 ).

Smoking abstinence was reported among 9.4\% on the whole sample (583 out of 6112 ): 9.4\% (502 out of 5301) of those with no aid; $8.2 \%$ (52 out of 621 ) of those using e-cigarettes, and $14.6 \%$ ( 29 out of 190 ) of those using other quitting methods (Table 2). Those using e-cigarettes were non-significantly less likely to report abstinence than those using no aid (adjusted PR $[\mathrm{aPR}]=0.81 ; 95 \% \mathrm{CI}=0.58-1.14$; Table 2 ) and users of other quitting methods were non-significantly more likely to report abstinence than no aid users ( $\mathrm{aPR}=1.42 ; 95 \% \mathrm{CI}=0.95-2.13$ ) (Table 2). Flipping the reference group to e-cigarette users, those using other quitting methods were significantly more likely to report abstinence than e-cigarette users ( $\mathrm{aPR}=1.76 ; 95 \% \mathrm{CI}=1.07-2.88$ ). Higher cessation rates in the multivariate analyses were only recorded among respondents with higher education level ( $\mathrm{aPR}=1.64 ; 95 \% \mathrm{CI}=1.30$ 2.06; Table 2).

\section{Discussion}

Ten percent of smokers who attempted to quit in Italy in 2014-2015 used e-cigarettes as an aid, three times higher than the proportion recorded in smokers who attempted using other more official quitting methods. Moreover, smokers who used e-cigarettes were no more

Table 1

Associations between characteristics of the sample and use of different quitting methods among respondents who tried to stop smoking in the last 12 months ( $\mathrm{N}=6112$ ).

\begin{tabular}{|c|c|c|c|c|}
\hline & No aid \% ${ }^{\mathrm{a}}(\mathrm{N})$ & E cigarette $\%$ a $(N)$ & Other quitting methods ${ }^{\mathrm{e}}{ }^{\mathrm{a}}(\mathrm{N})$ & p-Value \\
\hline Total & $86.4(5301)$ & $10.7(621)$ & $2.9(190)$ & \\
\hline \multicolumn{5}{|l|}{ Gender \% } \\
\hline Male & $85.9(2965)$ & $11.7(374)$ & $2.4(88)$ & \multirow[t]{2}{*}{0.0026} \\
\hline Female & $87.0(2336)$ & $9.3(247)$ & $3.7(102)$ & \\
\hline \multicolumn{5}{|l|}{ Age groups (years) } \\
\hline $18-34$ & 91.5 (1195) & $7.0(161)$ & $1.5(38)$ & \multirow[t]{3}{*}{$<0.001$} \\
\hline $35-49$ & $82.3(1776)$ & $14.1(283)$ & $3.6(76)$ & \\
\hline $50-69$ & $85.1(1530)$ & $10.9(177)$ & $4.0(76)$ & \\
\hline \multicolumn{5}{|l|}{ Education level $^{\mathrm{b}}$} \\
\hline High & $85.4(3168)$ & $11.4(358)$ & $3.2(107)$ & \multirow[t]{2}{*}{0.213} \\
\hline Low & $87.6(2129)$ & $9.6(263)$ & $2.8(83)$ & \\
\hline \multicolumn{5}{|l|}{ Economic status ${ }^{\mathrm{c}}$} \\
\hline None difficulties & $87.4(2109)$ & $9.6(215)$ & $3.0(70)$ & \multirow[t]{3}{*}{0.008} \\
\hline Some difficulties & $87.5(2179)$ & $9.7(243)$ & $2.8(74)$ & \\
\hline Many difficulties & $82.8(1003)$ & $14.0(162)$ & $3.2(46)$ & \\
\hline \multicolumn{5}{|l|}{ Geographic area } \\
\hline Northern Italy & $86.8(2590)$ & $9.9(275)$ & $3.3(94)$ & \multirow[t]{3}{*}{0.255} \\
\hline Central Italy & $84.7(1272)$ & $12.2(174)$ & $3.1(50)$ & \\
\hline South Italy and islands & $87.0(1439)$ & $10.6(172)$ & $2.4(46)$ & \\
\hline \multicolumn{5}{|l|}{ Cigarettes per day ${ }^{\mathrm{d}}$} \\
\hline Occasional smoker (<1 cig/day) & $95.6(178)$ & $2.3(5)$ & $2.1(4)$ & \multirow[t]{3}{*}{$<0.001$} \\
\hline Light smoker (1-19 cig/day) & $88.7(4181)$ & $8.7(403)$ & $2.6(125)$ & \\
\hline Heavy smoker ( $\geq 20 \mathrm{cig} /$ day) & $76.9(922)$ & $18.8(212)$ & $4.3(61)$ & \\
\hline
\end{tabular}

\footnotetext{
a Weighted percentages.

b 4 missing values.

c 11 missing values.

d 21 missing values.

e Smoking cessation medications; smoking cessation programmes delivered or not in National Health System Smoking Cessation Services; other unspecified methods.
} 
Table 2

Associations between quitting methods and abstinence.

\begin{tabular}{|c|c|c|c|}
\hline & \multicolumn{3}{|c|}{ Attempts to quit smoking in the last 12 months $(\mathrm{N}=6112)$} \\
\hline & Succeeded, N $\left(\%^{\mathrm{a}}\right)$ & Failed, $\mathrm{N}\left(\%^{\mathrm{a}}\right)$ & adjusted Prevalence Ratio (95\% IC) \\
\hline Total & $583(9.4)$ & $5529(90.6)$ & \\
\hline \multicolumn{4}{|l|}{ Sex } \\
\hline Men & $320(9.2)$ & $3107(90.8)$ & $1^{\mathrm{b}}$ \\
\hline Women & $263(9.7)$ & $2422(90.3)$ & $1.1(0.89-1.35)$ \\
\hline \multicolumn{4}{|l|}{ Age groups (years) } \\
\hline $18-34$ & $216(9.5)$ & $1978(90.5)$ & $1^{\mathrm{b}}$ \\
\hline $35-49$ & $208(9.3)$ & $1927(90.7)$ & $0.99(0.78-1.26)$ \\
\hline $50-69$ & $159(9.5)$ & $1624(90.5)$ & $1.06(0.83-1.35)$ \\
\hline \multicolumn{4}{|l|}{ Level of education } \\
\hline Low & $174(7.1)$ & $2301(92.9)$ & $1^{\mathrm{b}}$ \\
\hline High & $407(11.0)$ & $3226(89.0)$ & $1.64(1.30-2.06)$ \\
\hline \multicolumn{4}{|l|}{ Economic status } \\
\hline Many difficulties & $95(8.5)$ & $1116(91.5)$ & $1^{\mathrm{b}}$ \\
\hline Some difficulties & $215(8.4)$ & $2281(91.6)$ & $0.93(0.68-1.26)$ \\
\hline None difficulties & $269(11.1)$ & $2125(88.9)$ & $1.13(0.85-1.52)$ \\
\hline \multicolumn{4}{|l|}{ Geographic area } \\
\hline South Italy and islands & $142(8.4)$ & $1515(91.6)$ & $1^{\mathrm{b}}$ \\
\hline Central Italy & $141(9.3)$ & $1355(90.7)$ & $1.08(0.82-1.41)$ \\
\hline Northern Italy & $300(10.6)$ & $2659(89.4)$ & $1.25(0.99-1.58)$ \\
\hline \multicolumn{4}{|l|}{ Cigarettes per day (cig/day) } \\
\hline Occasional smoker ( $<1 \mathrm{cig} /$ day $)$ & $16(8.4)$ & $171(91.6)$ & 1 \\
\hline Light smokers (1-19 cig/day) & $412(8.6)$ & $4297(91.4)$ & $0.85(0.44-1.62)$ \\
\hline Heavy smokers ( $\geq 20$ cig/day) & $152(12.6)$ & $1043(87.4)$ & $1.69(1.32-2.16)$ \\
\hline \multicolumn{4}{|l|}{ Method to stop smoking } \\
\hline No aid & $502(9.4)$ & 4799 (90.6) & $1^{\mathrm{b}}$ \\
\hline E-cigarette & $52(8.2)$ & $569(91.8)$ & $0.81(0.58-1.14)$ \\
\hline Other quitting methods ${ }^{\mathrm{c}}$ & $29(14.6)$ & $161(85.4)$ & $1.42(0.95-2.13)$ \\
\hline
\end{tabular}

a Weighted percentages.

b Reference category.

c Medications; smoking cessation programmes delivered or not in National Health System Smoking Cessation Services, other unspecified methods.

likely to report abstinence than those who used no aid to stop smoking, but were less likely to report abstinence than users of established quitting methods. We were not able to collect figures on characteristics of ecigarettes used, so our results are to be taken with caution. In Italy, ecigarette availability determined an increase in quit attempts, according to the Passi survey: in 2012, at the beginning of the introduction of ecigarettes, $37.5 \%$ of smokers reported to have attempted to quit in the last year, whereas this proportion increased to 40.5\% in 2013 (The Italian behavioral risk factor surveillance system, n.d.). Moreover, a shift in the quitting methods used in the last attempt was recorded: unaided attempts decreased from $94 \%$ in 2012 to $87 \%$ in 2014-2015, whereas other quitting methods decreased from $6 \%$ in 2012 to $3 \%$ in 2014-2015 (The Italian behavioral risk factor surveillance system, n.d.). Similar trends were recorded in England after the introduction of e-cigarettes: quit attempts recorded an increase from 34.4\% in 2012 to $38.5 \%$ in 2013 , and there was a significant increase in e-cigarette use as quitting method (from $<5 \%$ in 2011 to around 35\% in 2015), and a significant decrease of licensed NRT use (from 40\%-45\% in 2011 to $25 \%$ in 2015) and of unaided quitting (from about $45 \%$ in 2011 to around 30\%-35\% in 2015) (www.smokinginengland.info, n.d.).

A previous study conducted in a representative sample of English population, showed that English smokers who used e-cigarettes as an aid to quit recorded higher cessation rates than those who tried to quit with no aid (Brown et al., 2014). In order to explain differences between results recorded in England and in Italy, it is important to take into account that characteristics of e-cigarette users were quite different among Italian and English population. In England less dependent smokers and those from higher social grades were more likely to use e-cigarettes (Brown et al., 2014), whereas in Italy heavy smokers and those with many economic difficulties tended to be more likely to use e-cigarettes than other smoking cessation methods. The use of cessation aids is less common in Italy than in England, given that in Italy smoking cessation aids are not reimbursable (Gorini et al., 2013). It is more expensive in Italy to use medications and to attend cessation programmes at NHS-SSSs than to buy e-cigarettes. Therefore, we do not expect our results to be easily applied to other Countries. However, this study provides useful evidence for national policies, and a useful and reliable benchmark for international comparison.

Major strengths of this study are the use of a large and representative sample of the Italian population, and the assessment of the use of e-cigarette as a quitting method. To our knowledge, this is one of the largest cross-sectional studies of real-world use of e-cigarettes, comparable with those conducted in England (Brown et al., 2014), and Kansas (Christensen et al., 2014).

The study had some limitations. First, we cannot rule out that one or more unknown confounders are responsible for these findings, although we adjusted the association between quitting methods and abstinence for known confounding factors. Second, as already stated, we did not collect any figures regarding the type of e-cigarette used (i.e., at least a categorization in the first, second or third generations of e-cigarettes), and details on the other smoking cessation methods, given that the PASSI survey had no room to expand the set of questions on smoking (Baldissera et al., 2011; The Italian behavioral risk factor surveillance system, n.d.; Baldissera et al., 2014). However, many of the studies on e-cigarettes shared the same limitations (Hartmann-Boyce et al., 2016; Kalkhoran and Glantz, 2016; Malas et al., 2016). Third, in order to obtain unbiased estimates of cessation rates, we removed respondents who quit smoking less than six months at the time of the interview, but we were not able to remove all quit attempts in the six months before the interview because the time of failed quit attempts was not recorded. Fourth, the overall proportion of successful quitters is higher (9\%) than that usually recorded for self-quitters (3-5\%) (Hughes et al., 2004). Smoking abstinence was self-reported and this could be a reason of such a high success rate. However, in cross-sectional surveys, is acceptable to use self-reported data (Wong et al., 2012). Maybe, asking by phone a question to a recent quitter regarding whether or not he/she succeeded, could have added an additional bias due to the uneasiness to declare to interviewers his/her failure. Fifth, 
we assessed nicotine dependence using only the number of cigarettes smoked per day. We could not use other more precise measures of nicotine dependence, such as Heavy Smoking Index [HSI] (Fagerström and Furberg, 2008). However, we used the number of cigarettes smoked per day that is one of the two measures used to estimate HSI.

In conclusion, among smokers trying to quit, e-cigarettes users were no more likely to report abstinence as those using no aid, but were less likely to report abstinence than users of established quitting methods.

Further studies are needed in order to understand the relationship between the type of e-cigarette used to quit and abstinence rates.

\section{Funding}

This work was supported by the Italian Ministry of Health/National Centre for Disease Prevention and Control (grant no. 6M32/2014-CCM).

\section{Conflict of interest}

None to declare.

\section{Transparency document}

The Transparency document associated with this article can be found, in the online version.

\section{Acknowledgments}

The authors thank the many regional referents and the regional and local coordinators who contributed to the data collection. A special thanks goes to the health care workers in the public health departments in the LHUs who conducted the interviews.

\section{References}

Smoking in Englandwww.smokinginengland.info (accessed 10 January 2017).

Adkison, S.E., O'Connor, R.J., Bansal-Travers, M., Hyland, A., Borland, R., Yong, H.H. Cummings, K.M., McNeill, A., Thrasher, J.F., Hammond, D., Fong, G.T., 2013. Electronic nicotine delivery systems: international tobacco control four-country survey. Am. J. Prev. Med. 44 (3):207-215. http://dx.doi.org/10.1016/j.amepre.2012.10.018.

Adriaens, K. Van Gucht, D. Declerck, P. Baeyens, F, 2014 Oct 29. Effectiveness of the electronic cigarette: an eight-week Flemish study with six-month follow-up on smoking reduction, craving and experienced benefits and complaints. Int. J. Environ. Res. Public Health 11:11220-11248. http://dx.doi.org/10.3390/ijerph111111220.

American Association for Public Opinion Research, 2008. Standard definitions: final dispositions of case codes and outcome rates for surveys. 5th edition. Lenexa (KS). http:// www.aapor.org/AM/Template.cfm?Section=Standard_Definitions\&Template=/CM ContentDisplay.cfm\&ContentID $=1273$ (Accessed 30 July 2013).

Baldissera, S., Campostrini, S., Binkin, N., et al., 2011. Features and initial assessment of the Italian behavioral risk factor surveillance system (PASSI), 2007-2008. Prev. Chronic Dis. 8, A24.

Baldissera, S., Ferrante, G., Quarchioni, E., et al., 2014. Field substitution of nonresponders can maintain sample size and structure without altering survey estimates-the experience of the Italian behavioral risk factors surveillance system (PASSI). Ann. Epidemiol. 24:241-245. http://dx.doi.org/10.1016/j.annepidem.2013.12.003.

Biener, L., Hargraves, J.L., 2015 Feb. A longitudinal study of electronic cigarette use among a population-based sample of adult smokers: association with smoking cessation and motivation to quit. Nicotine Tob. Res. 17:127-133. http://dx.doi.org/10.1093/ntr/ ntu200 (Epub 2014 Oct 9).

Brown, J., Beard, E., Kotz, D., Michie, S., West, R., 2014. Real-world effectiveness of e-cigarettes when used to aid smoking cessation: a cross-sectional population study. Addic tion 109:1531-1540. http://dx.doi.org/10.1111/add.12623.
Christensen, T., Welsh, E., Faseru, B., 2014. Profile of e-cigarette use and its relationship with cigarette quit attempts and abstinence in Kansas adults. Prev. Med. 69:90-94. http://dx.doi.org/10.1016/j.ypmed.2014.09.005 (Epub 2014 Sep 16).

Stata Corporation, 2013. Stata Statistical Software: Release 13.0. College Station, Texas.

D'Argenzio, A., D'Argenio, P., Ferrante, G., et al., 2011. 40\% of smokers try to stop smoking, only $8 \%$ succeed in. Epidemiol. Prev. 35, 362

Dawkins, L., Turner, J., Roberts, A., Soar, K., 2013. 'Vaping' profiles and preferences: an online survey of electronic cigarette users. Addiction 108:1115-1125. http://dx.doi.org/ 10.1111/add.12150 (Epub 2013 Mar 28).

Fagerström, K., Furberg, H., 2008. A comparison of the Fagerström test for nicotine dependence and smoking prevalence across countries. Addiction 103, 841-845.

Filippidis, F.T., Laverty, A.A., Gerovasili, V., Vardavas, C.I., 2017. Two-year trends and predictors of e-cigarette use in 27 European Union member states. Tob. Control. 26 (1): 98-104. http://dx.doi.org/10.1136/tobaccocontrol-2015-052771 (Epub 2016 May 24).

Gallus, S., Muttarak, R., Martínez-Sánchez, J.M., Zuccaro, P., Colombo, P., La Vecchia, C., 2011. Smoking prevalence and smoking attributable mortality in Italy, 2010. Prev. Med. 52 (6):434-438. http://dx.doi.org/10.1016/j.ypmed.2011.03.011.

Gallus, S., Lugo, A., Pacifici, R., Pichini, S., Colombo, P., Garattini, S., La Vecchia, C., 2014. Ecigarette awareness, use, and harm perceptions in Italy: a national representative survey. Nicotine Tob. Res. 16:1541-1548. http://dx.doi.org/10.1093/ntr/ntu124 (Epub 2014 Jul 31).

GBD 2013 Risk Factors CollaboratorsForouzanfar, M.H., Alexander, L., et al., 2015. Global, regional, and national comparative risk assessment of 79 behavioural, environmental and occupational, and metabolic risks or clusters of risks in 188 countries, 19902013: a systematic analysis for the Global Burden of Disease Study 2013. Lancet 386:2287-2323. http://dx.doi.org/10.1016/S0140-6736(15)00128-2 (Epub 2015 Sep 11).

Goniewicz, M.L. Lingas, E.O., Hajek, P., 2013. Patterns of electronic cigarette use and user beliefs about their safety and benefits: an internet survey. Drug Alcohol Rev. 32: 133-140. http://dx.doi.org/10.1111/j.1465-3362.2012.00512.x (Epub 2012 Sep 20).

Gorini, G., Ameglio, M., Martini, A., Bosi, S., Laezza, M., Gruppo Centri Antifumo, 2013. Volumes of services supplied by Italian stop-smoking services and their characteristics predictive of abstinence. Epidemiol. Prev. 37, 263-270.

Green, S.H., Bayer, R., Fairchild, A.L., 2016. Evidence, policy, and e-cigarettes-will England reframe the debate? N. Engl. J. Med. 374, 1301-1303.

Hartmann-Boyce, J., McRobbie, H., Bullen, C., Begh, R., Stead, L.F., Hajek, P., 2016. Electronic cigarettes for smoking cessation and reduction. Cochrane Database Syst. Rev. (9), CD010216 http://dx.doi.org/10.1002/14651858.CD010216.pub3.

Hughes, J.R., Keely, J., Naud, S., 2004. Shape of the relapse curve and long-term abstinence among untreated smokers. Addiction 99, 29-38.

Kalkhoran, S., Glantz, S.A., 2016. E-cigarettes and smoking cessation in real-world and clinical settings: a systematic review and meta-analysis. Lancet Respir. Med. 4: 116-128. http://dx.doi.org/10.1016/S2213-2600(15)00521-4 (Epub 2016 Jan 14).

Lechner, W.V., Tackett, A.P., Grant, D.M., Tahirkheli, N.N., Driskill, L.M., Wagener, T.L., 2015. Effects of duration of electronic cigarette use. Nicotine Tob. Res. 17:180-185. http://dx.doi.org/10.1093/ntr/ntu061 (Epub 2014 May 13).

Malas, M., van der Tempel, J., Schwartz, R., et al., 2016. Electronic cigarettes for smoking cessation: a systematic review. Nicotine Tob. Res. 18 (10):1926-1936. http://dx.doi. org/10.1093/ntr/ntw119 (Epub 2016 Apr 25).

Petersen, M.R., Deddens, J.A., 2008 Feb 28. A comparison of two methods for estimating prevalence ratios. BMC Med. Res. Methodol. 8:9. http://dx.doi.org/10.1186/14712288-8-9.

Polosa, R., Caponnetto, P., Maglia, M., Morjaria, J.B., Russo, C., 2014. Success rates with nicotine personal vaporizers: a prospective 6-month pilot study of smokers not intending to quit. BMC Public Health 14:1159. http://dx.doi.org/10.1186/14712458-14-1159.

Schoenborn, C.A., Gindi, R.M., 2015. Electronic cigarette use among adults: United States, 2014. NCHS Data Brief 217, 1-8.

Tackett, A.P., Lechner, W.V., Meier, E., Grant, D.M., Driskill, L.M., Tahirkheli, N.N., Wagener, T.L., 2015. Biochemically verified smoking cessation and vaping beliefs among vape store customers. Addiction 110 (5):868-874. http://dx.doi.org/10.1111/add.12878.

The Italian behavioral risk factor surveillance system, d. Passi (Progressi delle Aziende Sanitarie per la Salute in Italia - progress by local health units towards a healthier Italy)http://www.epicentro.iss.it/passi/en/english.asp (accessed 10 January 2017).

Wong, S.L., Shields, M., Leatherdale, S., Malaison, E., Hammond, D., 2012. Assessment of validity of self-reported smoking status. Health Rep. 23, 47-53.

Yeh, J.S., Bullen, C., Glantz, S.A., 2016. Clinical decisions. E-cigarettes and smoking cessation. N. Engl. J. Med. 374, 2172-2174.

Zou, G., 2004. A modified Poisson regression approach to prospective studies with binary data. Am. J. Epidemiol. 159, 702-706. 